Part of Journal of Research of the National Bureau of Standards, Volume 24, January 1940

\title{
INFRARED ARC SPECTRUM OF GERMANIUM
}

\author{
By C. C. Kiess
}

\section{ABSTRACT}

For theoretical reasons it is known that a portion of the arc spectrum of germanium must lie in the infrared. The more intense lines in this region have now been recorded on the specially sensitized plates of the Eastman series with the grating spectrographs of the National Bureau of Standards. Most of the new lines have been classified as combinations between the previously known ${ }^{3} \mathrm{P}^{\circ}$ and ${ }^{1} \mathrm{P}^{\circ}$ terms of the $5 s$ configuration with new triplet and singlet terms of the $5 p$ configuration. The yellow lines observed by Lunt in spark and discharge tube sources are found to be lines of Ge I and, in analogy with similar lines of $\mathrm{C}$ I and Si $\mathbf{r}$, probably owe their origin to the $5 s-6 p$ transition.

\section{CONTENTS}

Page

I. Introduction

II. Experimental procedure

III. Results

\section{INTRODUCTION}

The element germanium shares with gallium and scandium the distinction of having its existence foretold and its properties described prior to its actual discovery. In 1871 Mendeléeff announced his periodic classification of the chemical elements and predicted three new members to occupy the gaps in the table as it then existed. The final verification of his predictions occurred in 1886, when Winkler discovered a new element, germanium, with the properties ascribed by Mendeléeff to ekasilicon. The element is rare and only small amounts have been prepared in a pure state.

Investigations of the spectra emitted by germanium atoms in various states of excitation are summarized in volume 7 of Kayser's Handbuch der Spectroscopie. Since the preparation of this work in 1927, several more papers have appeared - three papers by Lang $^{1}$ and one by Rao and Narayan," who describe the series of GeII, GeIII, and GeIv; a paper by Rao, ${ }^{3}$ who describes the arc spectrum in the Schumann region and gives a revised term analysis of Ger; and a paper by Sibaiya, ${ }^{4}$ who finds that certain lines of Ger reveal no hyperfine structure.

Rao's analysis of GeI describes that portion of the spectrum that is built up on the terms ${ }^{3} \mathrm{P},{ }^{1} \mathrm{D}$, and ${ }^{1} \mathrm{~S}$ of the basic configuration $4 s^{2} 4 p^{2}$ of the neutral atom. That part of the spectrum resulting from combinations between high terms and lower terms of various

1 R. J. Lang, Phys. Rev. 30, 762 (1927); Proc. Nat. Acad. Scl. 14, 32 (1928); Phys. Rev. 34, 696 (1929).

2 K. R. Rao and A. L. Narayan, Proc. Roy. Soc. (London) [A] 119, 607 (1928).

3 R. K. Rao, Proc. Roy. Soc. (London) [A] 124, 465 (1929).

4. Sibaiya, Current Sci. 6, 152 (1937). 
excited states has not yet been described. Prominent among the terms of the excited states are $5 s^{3} \mathrm{P}$ and $5 s^{1} \mathrm{P}$. In analogy with the structures that have been found for $\mathrm{CI}^{5}$ and $\mathrm{Sir}^{6}{ }^{6}$ we may expect for GeI groups of lines in the infrared and in the yellow that represent the combinations between the higher terms of the $4 s^{2} 4 p n p$ configurations with the $5 s$ terms. It is the purpose of this paper to describe the results that have been obtained in a survey of the germanium arc spectrum throughout the yellow, red, and infrared regions photographically accessible.

\section{EXPERIMENTAL PROCEDURE}

The spectrograms upon which the present investigation is based were secured with the grating spectrographs of the National Bureau of Standards. For the infrared region, the grating ruled by Anderson with 7,500 lines per inch was employed. For the shorter regions, gratings ruled by Wood with 15,000 and 30,000 lines per inch were employed. For each spectral region to be recorded, the appropriate sensitized plate of the Eastman series was used.

The light source was an arc between copper or silver electrodes to which small amounts of $\mathrm{GeO}_{2}$ were added. The arc was maintained at 6 or 7 amperes from 220-volt d-c mains, and operated with a fair degree of steadiness during the exposure periods, which ranged from 10 or 15 minutes for the yellow region to 3 hours for the infrared. Exposures to the iron arc were juxtaposed to the germanium exposures to furnish the wave-length standards required in the reductions of the measurements. The values of the standards were selected from the lists adopted by the International Astronomical Union ${ }^{7}$ or from those measured by Meggers. ${ }^{8}$

\section{RESULTS}

The new wave lengths of Ge I are presented in table 1, in which each entry represents the mean of two to six measurements. The infrared lines are sharp, only a few presenting a slightly hazy or widened appearance. This latter characteristic is indicated in the table by the letter $h$. On the other hand, the yellow lines are diffuse, many of them exhibiting an asymmetrical shading toward longer wave lengths. The intensities assigned to the lines are the usual visual estimates, and are not comparable between widely separated regions of the spectrum.

\footnotetext{
${ }^{5}$ A. Fowler and E.W.H. Selwyn, Proc. Roy. Soc. (London) [A] 118, 34 (1928); F. Paschen and G. Kruger, Ann. Physik [5] 7, 1 (1930).

6 C. C. Kiess, J. Research NBS 21, 185 (1938) RP1124.

7 Trans. Int. Astron. Union 3, 77 (1928).

8 W. F. Meggers, J. Research NBS 14, 33 (1935) RP755.
} 
TABLE 1.-Wave lengths in the arc spectrum of germanium

\begin{tabular}{|c|c|c|c|}
\hline$\lambda_{\text {air }} \mathrm{A}$ & $\begin{array}{l}\text { Inten- } \\
\text { sity }\end{array}$ & $\nu_{\mathrm{rac}} \mathrm{cm}^{-1}$ & Term combination \\
\hline $\begin{array}{l}11144.80 \\
11125.28 \\
11040.09 \\
11030.88 \\
10947.51\end{array}$ & $\begin{array}{r}2 \\
25 \\
1 \\
2 \\
30\end{array}$ & $\begin{array}{l}8970.34 \\
8986.08 \\
9055.42 \\
9062.98 \\
9132.00\end{array}$ & $\begin{array}{l}5 s^{3} \mathrm{P}_{2}^{\circ}-5 p p^{3} \mathrm{P}_{1} \\
5 s^{3} \mathbf{P}_{2}^{\circ}-5 p p^{3} \mathrm{D}_{3} \\
5 s^{1} \mathrm{P}_{1}^{\circ}-5 p p^{3} \mathrm{~S}_{1} \\
5 s^{3} \mathrm{P}_{1}^{\circ}-5 p^{3} \mathrm{D}^{1} \\
5 s^{8} \mathrm{P}_{1}^{\circ}-5 p^{3} \mathrm{D}_{2}\end{array}$ \\
\hline $\begin{array}{l}\text { 10734. } 14 \\
10731.80 \\
10576.70 \\
10459.70 \\
10405.05\end{array}$ & $\begin{array}{r}25 \\
1 \\
5 \\
1 \\
40\end{array}$ & $\begin{array}{l}\text { 9313. } 52 \\
9315.55 \\
9452.15 \\
9557.89 \\
9608.09\end{array}$ & $5 s^{3} \mathrm{P}_{0}^{0}-5 p^{3} \mathrm{D}_{1}$ \\
\hline $\begin{array}{r}10382.54 \\
10305.24 \\
10201.00 \\
10039.48 \\
9957.65\end{array}$ & $\begin{array}{r}20 \\
1 \\
8 \\
20 \\
1\end{array}$ & $\begin{array}{r}9628.90 \\
9701.15 \\
9800.27 \\
9957.95 \\
10039.78\end{array}$ & $\begin{array}{l}5 s^{1} \mathrm{P}_{1}^{\circ}-5 p{ }^{1} \mathrm{D}_{2} \\
5 s^{3} \mathrm{P}_{1}^{\circ}-5 p p^{3} \mathrm{P}_{0} \\
5 s^{3} \mathrm{P}_{2}^{\circ}-5 p p^{3} \mathrm{~S}_{1}\end{array}$ \\
\hline $\begin{array}{l}\text { 9844. } 16 \\
9625.72 \\
9492.59 \\
9398.93 \\
9233.40\end{array}$ & $\begin{array}{c}0 \\
35 \\
10 \\
20 \\
1 h\end{array}$ & $\begin{array}{l}10155.52 \\
10385.99 \\
10531.65 \\
10636.59 \\
10826.57\end{array}$ & $\begin{array}{l}5 s^{3} \mathrm{P}_{1}-5 p^{3} \mathrm{P}_{1} \\
5 s^{3} \mathrm{P}_{2}^{0}-5 p^{1} \mathrm{D}_{2} \\
5 s^{3} \mathrm{P}_{0}^{0}-5 p^{3} \mathrm{P}_{1} \\
5 p^{3} \mathrm{D}_{3}-7 s^{3} \mathrm{P}_{2}^{0}\end{array}$ \\
\hline $\begin{array}{l}9096.13 \\
9068.87 \\
8789.87 \\
8367.85 \\
8256.14\end{array}$ & $\begin{array}{r}25 \\
15 \\
5 \\
3 \\
4 h\end{array}$ & $\begin{array}{l}10990.67 \\
11023.72 \\
11373.62 \\
11947.22 \\
12108.87\end{array}$ & $\begin{array}{l}5 s^{1} \mathrm{P}_{i}-5 p p^{1} \mathrm{~S}_{0}^{\circ} \\
5 s^{3} \mathrm{P}_{1}^{\circ}-5 p^{3} \mathrm{P}_{2} \\
5 s^{3} \mathrm{P}_{1}^{\circ}-5 p^{3} \mathrm{~S}_{1} \\
5 s^{3} \mathrm{P}_{1}^{\circ}-5 p^{1} \mathrm{D}_{2}\end{array}$ \\
\hline $\begin{array}{l}8031.15 \\
7833.56 \\
7511.55 \\
6557.74 \\
5967.78\end{array}$ & $\begin{array}{l}8 h \\
7 h \\
2 h \\
3 h \\
4 h l\end{array}$ & $\begin{array}{l}12448.10 \\
12762.08 \\
13309.17 \\
15244.93 \\
16752.02\end{array}$ & $\begin{array}{l}5 s^{3} \mathrm{P}_{\mathrm{i}}-5 p^{1} \mathrm{~S}_{0} \\
5 s^{1} \mathrm{P}_{1}^{\circ}-6 p^{3} \mathrm{D}_{2}\end{array}$ \\
\hline $\begin{array}{l}5802.23 \\
5801.18 \\
5718.08 \\
5701.84 \\
5692.06\end{array}$ & $\begin{array}{c}50 h l \\
4 h \\
1 h l \\
3 h l \\
50 h l\end{array}$ & $\begin{array}{l}17229.99 \\
17233.10 \\
17483.55 \\
17533.47 \\
17563.47\end{array}$ & $\begin{array}{l}5 s^{1} \mathrm{P}_{1}^{\circ}-6 p^{1} \mathrm{D}_{2} \\
5 s^{3} \mathrm{P}_{1}-6 p^{3} \mathrm{D}_{1} \\
5 s^{3} \mathrm{P}_{1}^{\circ}-6 p^{8} \mathrm{D}_{2}\end{array}$ \\
\hline $\begin{array}{l}5664.90 \\
5664.27 \\
5656.08 \\
5621.59 \\
5616.00\end{array}$ & $\begin{array}{l}15 h l \\
12 h l \\
25 h l \\
20 h l \\
1 h\end{array}$ & $\begin{array}{l}17647.68 \\
17649.64 \\
17675.20 \\
17783.64 \\
17801.34\end{array}$ & $5 s^{3} \mathrm{P}_{0}^{\circ}-6 p^{3} \mathrm{D}_{1}$ \\
\hline $\begin{array}{l}5606.94 \\
5564.88 \\
5513.35 \\
5265.91\end{array}$ & $\begin{array}{l}25 h \\
15 h l \\
5 h l \\
2 h\end{array}$ & $\begin{array}{l}17830.10 \\
17964.86 \\
18132.77 \\
18984.80\end{array}$ & $5 s^{3} \mathrm{P}_{2}^{\circ}-6 p^{1} \mathrm{D}_{2}$ \\
\hline
\end{tabular}


When the wave numbers of the new infrared lines were differenced, it was seen that they exhibited the separations of the ${ }^{3} \mathrm{P}$ and ${ }^{1} \mathrm{P}$ terms of the $5 s$ configuration. This led to the detection of the $5 p$ terms, as listed in table 2, with numerical values based on those given by Rro. For the present, the component ${ }^{3} \mathrm{P}_{0}$ must be regarded as provisional owing to the nonappearance of other combinations necessary to establish it with certainty. The absence of the term $5 p^{1} \mathrm{P}$ must also be regarded as surprising in view of the intensity with which the analogous term appears in $\mathrm{Si}$ I and $\mathrm{C}_{\mathrm{I}}$.

TABLE 2.-np terms of Ge I

\begin{tabular}{|c|c|c|c|c|}
\hline \multirow{2}{*}{$\begin{array}{c}\text { Term } \\
\text { symbol }\end{array}$} & \multicolumn{2}{|c|}{$n=5$} & \multicolumn{2}{|c|}{$n=6$} \\
\hline & Term value & $\Delta \nu$ & Term value & $\Delta \nu$ \\
\hline${ }^{3} \mathrm{D}_{3}$ & 17454.25 & 106050 & - & \\
\hline${ }^{3} \mathrm{D}_{2}$ & 18723.84 & 1209.59 & 10292.53 & 3007 \\
\hline${ }^{3} \mathrm{D}_{1}$ & 18792. 88 & & 10322.60 & \\
\hline${ }^{3} \mathrm{P}_{2}$ & 16832. 20 & 637.70 & $\ldots$ & \\
\hline${ }^{2} \mathrm{P}_{1}$ & 17469.90 & 58568 & $\cdots-\cdots$ & \\
\hline${ }^{3} \mathrm{P}_{0}$ & 18055.58 & & 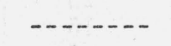 & \\
\hline${ }^{3} \mathrm{~S}_{1}$ & 16482. 28 & & & \\
\hline${ }^{1 D_{2}}$ & 15908. 70 & & 8307.50 & \\
\hline $\begin{array}{l}{ }^{1} \mathrm{~S}_{0}{ }^{1} \\
{ }^{2}\end{array}$ & 14546.82 & & - non & \\
\hline
\end{tabular}

The green and yellow lines between 5200 and $6000 \mathrm{~A}$ are identical with those previously observed by Lunt. ${ }^{\circ}$ In his experiments with sparks between metallic electrodes and with discharges through Geissler tubes containing $\mathrm{GeCl}_{4}$, these lines appeared under conditions favorable for the excitation of the neutral atom. The recent experiments at the National Bureau of Standards make it certain that they are emitted by neutral and not ionized atoms. Apparently they are the counterparts of similar groups in $\mathrm{Si}$ I and $\mathrm{C}_{\mathrm{I}}$ and represent the transition $5 s-6 p$. However, the satellite lines necessary to establish the multiplets with certainty are not present, and the classifications given for some of them, in table 1, must be regarded as provisional. The terms on which these tentative assignments are based were suggested by the occurrence among these lines of the $5 s$ differences 250 , 903 , and $2,318 \mathrm{~cm}^{-1}$.

The new terms that have resulted from this investigation belong to the $n p$ electron configurations. They are presented in table 2 . According to Hund's theory, the terms ${ }^{3} \mathrm{P}_{0},{ }^{3} \mathrm{P}_{1},{ }^{3} \mathrm{D}_{1}$, and ${ }^{3} \mathrm{D}_{2}$ owe their origin to the binding of a $p$ electron to the ${ }^{2} \mathrm{P}_{01 / 3}^{\circ}$ state of $\mathrm{Ge}^{+}$; the others, including all the singlets, have ${ }^{2} \mathrm{P}_{11 / 2}^{\circ}$ as their parent term.

\footnotetext{
IJ. Lunt, Monthly Notices Roy. Astron. Soc. 85, 38 (1924).
} 
The $5 p{ }^{3} \mathrm{D}$ terms show clearly that they originate in the manner required by theory; the $5 p^{3} \mathrm{P}$ terms exhibit this feature to a lesser degree. Accepting these facts as a guide, it would be possible to derive a complete set of terms for the $6 p$ configuration; but for the present it seems more desirable to await the evidence of future observations.

While the work described in this paper was in progress, the wave lengths of some Ge Ir lines, in the yellow and red, were measured several times. These lines appeared only at the poles of the arc and were clearly distinguishable from the Ge I lines. The mean values of these determinations are presented at this time, in table 3 , to complete the observational record.

TABLE 3.-Wave lengths of some Ge II lines

\begin{tabular}{|c|c|c|c|c|}
\hline $\begin{array}{l}\text { Wave } \\
\text { length }\end{array}$ & $\begin{array}{l}\text { Inten- } \\
\text { sity }\end{array}$ & $\begin{array}{l}\text { Wave num- } \\
\text { ber }\end{array}$ & $\Delta \nu$ & Term combination \\
\hline $\begin{array}{l}7145.42 \\
7049.45 \\
6966.42\end{array}$ & $\begin{array}{r}7 \\
10 \\
1\end{array}$ & $\begin{array}{l}13991.13 \\
14181.60 \\
14350.62\end{array}$ & 359.49 & 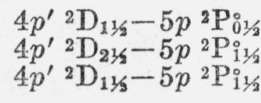 \\
\hline 6484. 26 & $7 h$ & 15417. 71 & & $5 p^{2} \mathrm{P}_{11 / 3}-6 s^{2} \mathrm{~S}_{01 / 2}$ \\
\hline 6336.46 & $4 h$ & 15777.33 & & $5 p^{2} \mathrm{P}_{01 / 2}-6 s{ }^{2} \mathrm{~S}_{01 / 2}$ \\
\hline 6021.09 & 20 & 16603. 70 & & $5 s^{2} \mathrm{~S}_{03 / 2}-5 p{ }^{2} \mathrm{P}_{03 / 2}^{\circ}$ \\
\hline 5893.42 & 25 & 16963. 38 & 000.00 & $5 s^{2} \mathrm{~S}_{01 / 2}-5 p{ }^{2} \mathrm{P}_{1 / 2}$ \\
\hline
\end{tabular}

Washington, November 28, 1939. 